\title{
PEMINDAHAN TAPING FASA UNTUK PENYEIMBANGAN BEBAN PADA JARINGAN 3 FASA DENGAN MENDETEKSI ARUS NETRAL BERBASIS ARDUINO MEGA 2560
}

\author{
Pandu Wicaksana, Saiful Manan \\ Program Studi Diploma III Teknik Elektro \\ Sekolah Vokasi, Universitas Diponegoro
}

\begin{abstract}
Pandu Wicaksana, Saiful Manan, in this paper explain that the load balance on the 3 phase 4 wire distribution system is very important. Continuous load imbalances can cause a decrease in the reliability of the electric power system and the quality of electrical energy. One consequence of an unbalanced load is the presence of a current flowing in a neutral introduction. The purpose of this study is to find out and analyze the current in a neutral conductor when the load conditions are unbalanced and when balanced. Load balancing is done by manual-remote, which means that the transfer of taping at a load is done by pressing the button that has been integrated with the HMI display. This software is also responsible for displaying current output from the sensor. That way, it can be seen that the current value of the neutral conductor before and after load balancing is done. That the current value of the neutral conductor will be smaller when the load is balanced compared to when the load between phases is not balanced.
\end{abstract}

Keywords: Unbalanced Load, Neutral Flow, SCADA, load balancing

\section{PENDAHULUAN \\ Latar Belakang}

Dalam pendistribusian tenaga listrik harus diusahakan sebaik mungkin, untuk itu gangguan yang terjadi pada sistem distribusi harus di selesaikan secara tepat dan cepat.

Sistem distribusi yang digunakan di Jawa Tengah menggunakan system 3 fasa dengan 4 kawat yang terdiri dari 3 kawat fasa dan 1 kawat netral. Dengan pentanahan netral secara langsung dengan penghantar netral diketanahkan sepanjang jaringan. Konstruksi jaringan yang terdiri dari saluran utama ini memiliki saluran cabang yang dapat berupa saluran 3 fasa 4 kawat, ataupun 1 fasa 2 kawat. Saluran ini digunakan karena lebih menguntungkan dari segi investasi. Akan tetapi menyebabkan beban suatu jaringan 3 fasa menjadi tidak seimbang, karena seiring dengan berjalannya waktu dan perkembangan wilayah, tiap fasa akan memiliki perkembangan pembebanan yang berbeda-beda.

Ketidakseimbangan secara terus menerus dapat menyebabkan penurunan keandalan system tenaga listrik dan kualitas energi listrik pada gardu induk serta menyebabkan kerusakan peralatan listrik. Untuk itu diperlukan suatu metode yang dapat mengurangi pembebanan yang tidak seimbang. Salah satu solusinya adalah dengan menyeimbangkan beban di jaringan 3 fasa yang dilakukan dengan pemindahan saluran cabang 1 fasa. Penyeimbangan beban dimaksudkan agar meminimalkan arus netral yang muncul. Proses menyeimbangkan beban di PT. PLN (persero) dilakukan dengan manual yaitu dengan cara memindah taping dari fasa yang berlebihan ke fasa yang masih bisa di bebani.
Dengan memanfaatkan Arduino sebagai pusat kontrol dan pengolah data, sehingga untuk memantau arus pada suatu jaringan maupun melakukan taping fasa di lapangan, cukup dengan memantau dan mengoperasikannya melalui tampilan HMI.

\section{Permasalahan}

Yang menjadi permasalahan adalah :

- Jaringan distribusi yang digunakan adalah jaringan distribusi 4 kawat karena konfigurasi jaringan yang digunakan sebagai data ada di wilayah distribusi jawa tengah yang menggunakan konfigurasi jaringan 4 kawat.

- Arus netral yang muncul disebabkan oleh beban tak seimbang pada tiap fasa. Bukan karena arus gangguan lainnya karena arus gangguan sudah masuk dalam sistem proteksi distribusi standar yaitu OCR dan GFR.

- Data yang digunakan adalah data arus beban.

- Mikrokontroller Arduino Mega 2560 digunakan sebagai pusat kontrol dan pengolah data untuk pemindahan taping fasa guna penyeimbang beban.

\section{Sistem Distribusi Tenaga Listrik}

Unit distribusi tenaga listrik dalam hal ini berfungsi untuk menyalurkan dan mendistribusikan tenaga listrik dari pusat pusat suplai atau Gardu Induk ke pusat-pusat beban yang berupa gardu gardu distribusi (gardu transformator) atau secara langsung mensuplai tenaga listrik ke konsumen dengan mutu yang memadai.

Tiga pola utama sistim pentanahan di jaringan distribusi $20 \mathrm{kV}$ ditinjau dari besarnya tahanan 
pentanahan, sistem pengetanahan jaringan menengah dapat diklasifikasikan seperti berikut :

- Pengetanahan Tahanan rendah yang dipakai pada saluran kabel atau kabel tanah (SKTM) tegangan menengah $20 \mathrm{kV}$ untuk sistem 3 phasa 3 kawat. Dipakai PLN wilayah kerja DKI Jaya dan Jawa Barat.

- Pengetanahan Tahanan tinggi yang dipakai pada saluran udara tegangan menengah $20 \mathrm{kV}$ untuk system 3 phasa 3 kawat. Dipakai PLN wilayah kerja Jawa Timur.

- Pengetanahan langsung tanpa impedansi dengan menggabungkan antara kawat netral dengan grounding pada banyak titik sepanjang jaringan (multi grounded common netral). Dipakai PLN wilayah kerja Jawa Tengah dan DI Yogyakarta. Tahanan tanah harus rendah 0,5 sampai dengan $1 \mathrm{ohm}$. Sistem kelistrikan dengan sistem pentanahan langsung. Sistem 3 fasa 4 kawat, kabel netral dapat langsung ditanahkan secara langsung.

\section{Sistem 3 fasa dan Keseimbangan Beban}

Sistem listrik banyak yang dibangun dengan sistem 3 fasa. Hal ini didasarkan pada alasan kehandalan aliran daya pada beban. Tegangan dan arus keluaran dari transformator dapat dibedakan berdasarkan hubungan antar belitannya, yaitu hubungan bintang $(\mathrm{Y})$ dan Delta $(\Delta)$. Hubungan $\mathrm{Y}$ merupakan sistem sambungan pada sistem tiga fasa yang menggunakan empat kawat, yaitu fasa $R, S, T$, dan N.

Yang dimaskud dengan keadaan seimbang adalah suatu keadaan dimana:

- Ketiga vektor arus/tegangan adalah sama besar.

- Ketiga vektor saling membentuk sudut $120^{\circ}$ satu sama lain, seperti yang terlihat pada gambar 1.

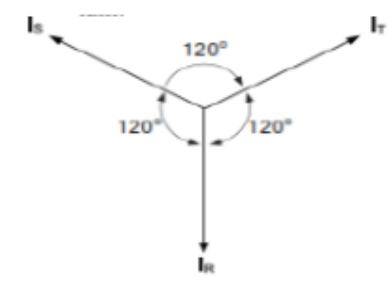

Gambar 1. Vektor Diagram Arus Keadaan Seimbang

\section{Arus Netral}

Arus netral dalam sistem distribusi tenaga listrik dikenal sebagai arus yang mengalir pada kawat netral di sistem distribusi tegangan menengah tiga fasa empat kawat. Arus netral ini muncul jika kondisi beban tidak seimbang. Penyebab muncul arus netral karena beban tidak seimbang seperti karena pemasangan baru tanpa memperhitungan fasa mana yang akan di gunakan.

\section{Mikrokontroler Arduino Mega 2560}

Arduino Mega 2560 adalah papan mikrokontroler berbasiskan Atmega 2560 yang memiliki 54 pin digital input/output, dimana 15 pin diantaranya digunakan sebagai output PWM, 16 pin sebagai input analog, 4 pin sebagai UART (port serial hardware), sebuah osilator kristal $16 \mathrm{MHz}$, koneksi USB, jack power, header ISCP, dan tombol reset $^{[4]}$.

Mikrokontroler itu sendiri adalah chip atau Integrated Circuit (IC) yang bisa diprogram menggunakan komputer. Tujuan ditanamkannya program pada mikrokontroler adalah supaya rangkaian elektronik dapat membaca input, kemudian memproses input tersebut sehingga menghasilkan output yang sesuai dengan keinginan. Jadi mikrokontroler berfungsi sebagai otak yang mengatur input, proses, dan output sebuah rangkaian elektronik. Arduino Mega 2560 ditunjukkan pada gambar 2 .

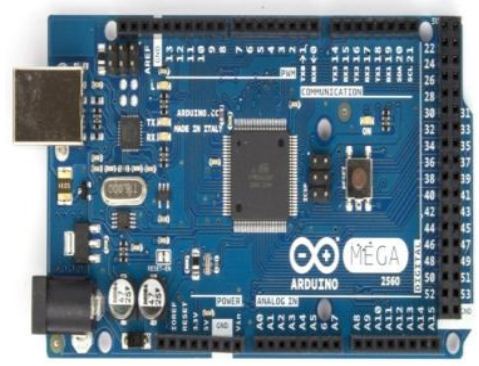

Gambar 2. Arduino Mega 2560

\section{PERANCANGAN SISTEM} sistem

Gambar 3 merupakan blok diagram dari

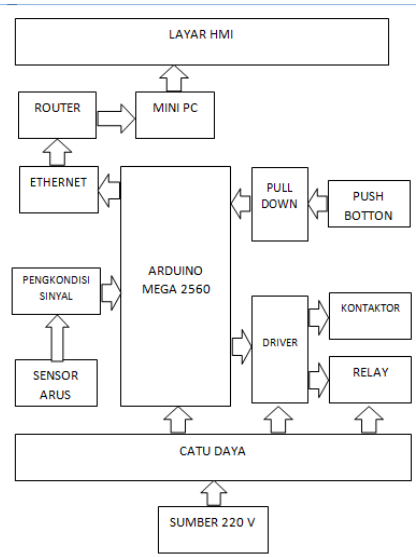

Gambar 3. Blok Diagram Sistem

\section{Rangkaian Catu Daya}

Ragkaian Catu Daya dibagi menjadi 2 tegangan yaitu 12 VDC dan 5VDC, untuk tegangan 12 VDC digunakan untuk mensuplai tegangan pada Arduino Mega 2560, dan Rangkaian Driver Relay. Sedangkan untuk tegangan 5 VDC digunakan untuk mensuplai sensor arus ACS712 dan rangkaian pull down. Jenis Rangkaian Catu Daya yang digunakan adalah rangkaian Catu Daya Simetris. Rangkaian catu daya ditunjukkan pafa gambar 4 . 


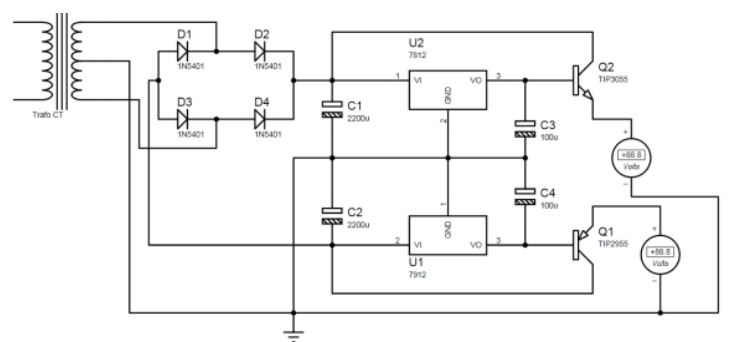

Gambar 4. Rangkaian Catu Daya

\section{Sensor Arus ACS712}

Sensor arus ACS712 digunakan untuk mendeteksi berapa arus yang mengalir pada setiap fasa dan pada kawat netral. Sensor arus yang digunakan sebanyak 4 buah.

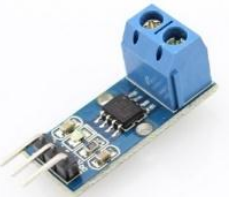

Gambar 5. Bentuk fisik ACS 712

\section{Rangkaian Driver Relay}

Rangkaian driver merupakan rangkaian output dari mikokontroler Arduino Mega 2560 digunakan untuk memicu tegangan koil pada relai. Rangkaian driver menggunakan IC ULN2803. Gambar 6 merupakan gambar driver relay yang dimaksud.

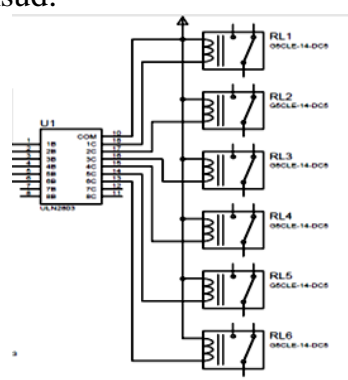

Gambar 6. Driver Relay

\section{Relay}

Relay yang digunakan menggunakan relay HKE 12VDC dengan jenis SPDT yang berarti mempunyai 1 kontak dan 2 kondisi yang dimiliki kontaknya.

\section{Rangkaian Driver Kontaktor}

Rangkaian Driver Kontaktor merupakan rangkaian yang digunakan untuk menghubungkan dan memutuskan tegangan jala jala ke kontaktor, seperti yang ditunjukkan pada gambar 7 .

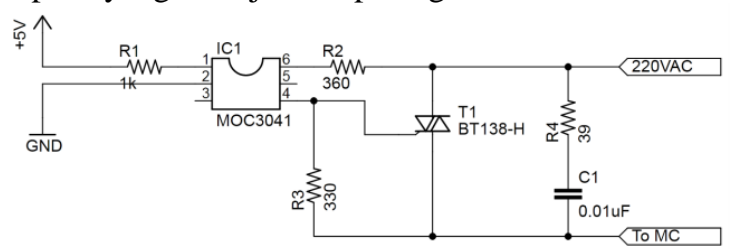

Gambar 7. Driver Kontaktor

\section{Rangkaian Pull Down}

Rangkaian Pull Down Resistor, seperti pada gambar 8, digunakan pada Push Button. Rangkaian ini memiliki konsep dimana saat keadaan push button ditekan, maka akan menghasilkan output yang bernilai high, sedangkan saat keadaan terbuka, output yang dihasilkan oleh rangkaian tersebut akan bernilai low.

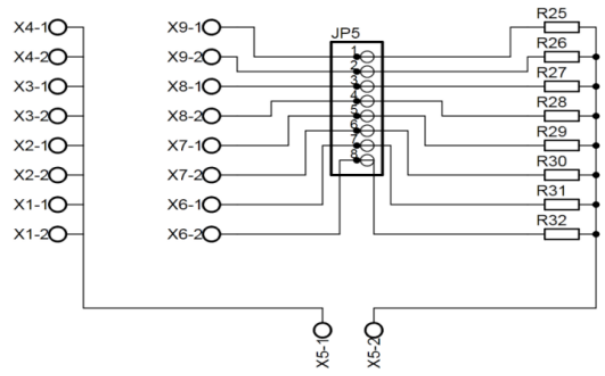

Gambar 8. Rangkain Pull Down

\section{Ethernet Shield}

Ethernet shield digunakan untuk menambah kemampuan Arduino Mega 2560 terhubung dengan SCADA menggunakan Modbus TCP/IP.

\section{Router}

Router berfungsi untuk menghubungkan mikrokontroller Arduino Mega 2560 dengan PC (Personal Computer) melalui jaringa TCP/IP.

\section{PERANCANGAN PERNGKAT LUNAK}

Diagaram alur dari sistem ini ditunjukkan melalui gambar flowchat seperti pada gambar 9.

\section{PENGUKURAN} dan 3 .

Hasil pengukuran ditunjukkan pada tabel 1,2

Dari tabel pengukuran dapat dilihat mana kombinasi beban saat dalam keadaan seimbang dan dalam keadaan tidak seimbang, dengan cara melihat kondisi kontaktor apakah On ataupun Trip. Dapat dilihat dalam kombinasi beban juga, bahwa dalam keadaan beban tak seimbang pun terdapat batas toleransi sehingga sistem tetap berjalan dengan normal. Kecuali jika sudah diatas nilai toleransi maka, kontaktor akan trip. Jika diambil nilai arus netral, kontaktor akan trip saat arus netral membaca lebih dari 0,45 A, sehingga apabila terbaca dibawah 0,45 A kontaktor akan tetap On sehingga sistem akan berjalan normal. 


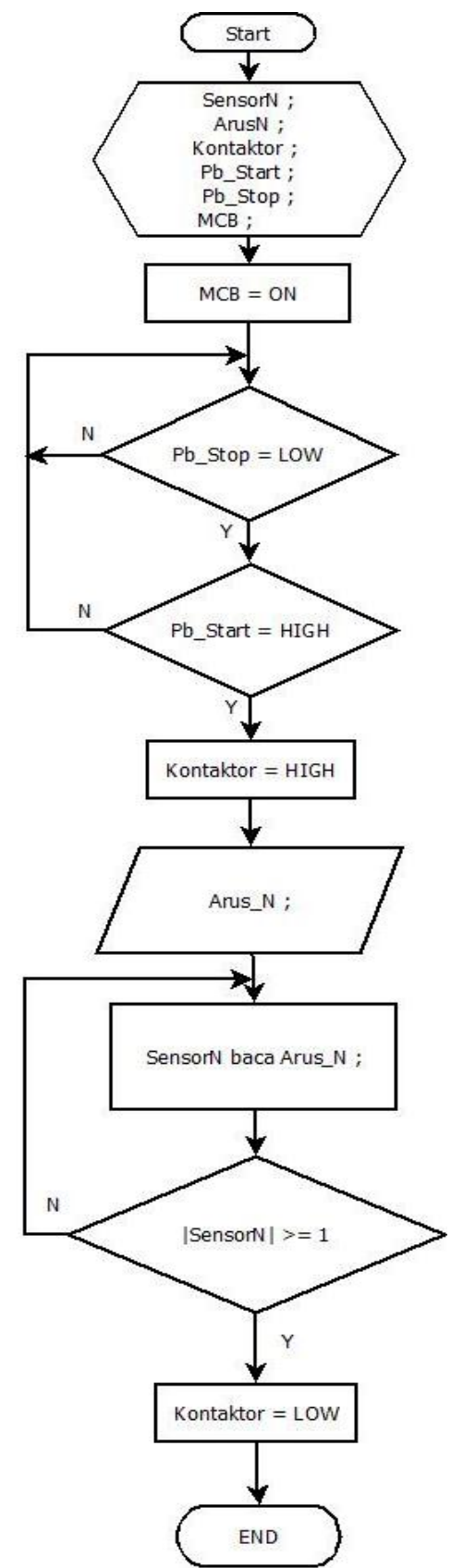

Gambar 9. Flowchart Gangguan pada Arus Netral

Tabel 1. Variasi beban tidak seimbang

\begin{tabular}{|c|c|c|c|c|}
\hline No & Fasa & $\begin{array}{l}\text { Beban } \\
\text { Watt }\end{array}$ & $\begin{array}{c}\text { Arus di } \\
\text { Tang } \\
\text { Ampere }\end{array}$ & $\begin{array}{c}\text { Arus di } \\
\text { Scada }\end{array}$ \\
\hline \multirow[t]{4}{*}{1} & $\mathrm{R}$ & 50Watt & 0.3 & 0.25 \\
\hline & $S$ & 160Watt & 0.7 & 0.74 \\
\hline & $\mathrm{T}$ & 160 Watt & 0.7 & 0.74 \\
\hline & $\mathrm{N}$ & & 0.4 & 0.44 \\
\hline \multirow[t]{4}{*}{2} & $\mathrm{R}$ & 200 Watt & 0.8 & 0.91 \\
\hline & S & 120 Watt & 0,5 & 0.56 \\
\hline & $\mathrm{T}$ & 50 Watt & 0.3 & 0.25 \\
\hline & $\mathrm{N}$ & & 0.6 & 0.6 \\
\hline \multirow[t]{2}{*}{3} & $\mathrm{R}$ & 85 Watt & 0,4 & 0,38 \\
\hline & S & 200 Watt & 0,8 & 0,86 \\
\hline
\end{tabular}

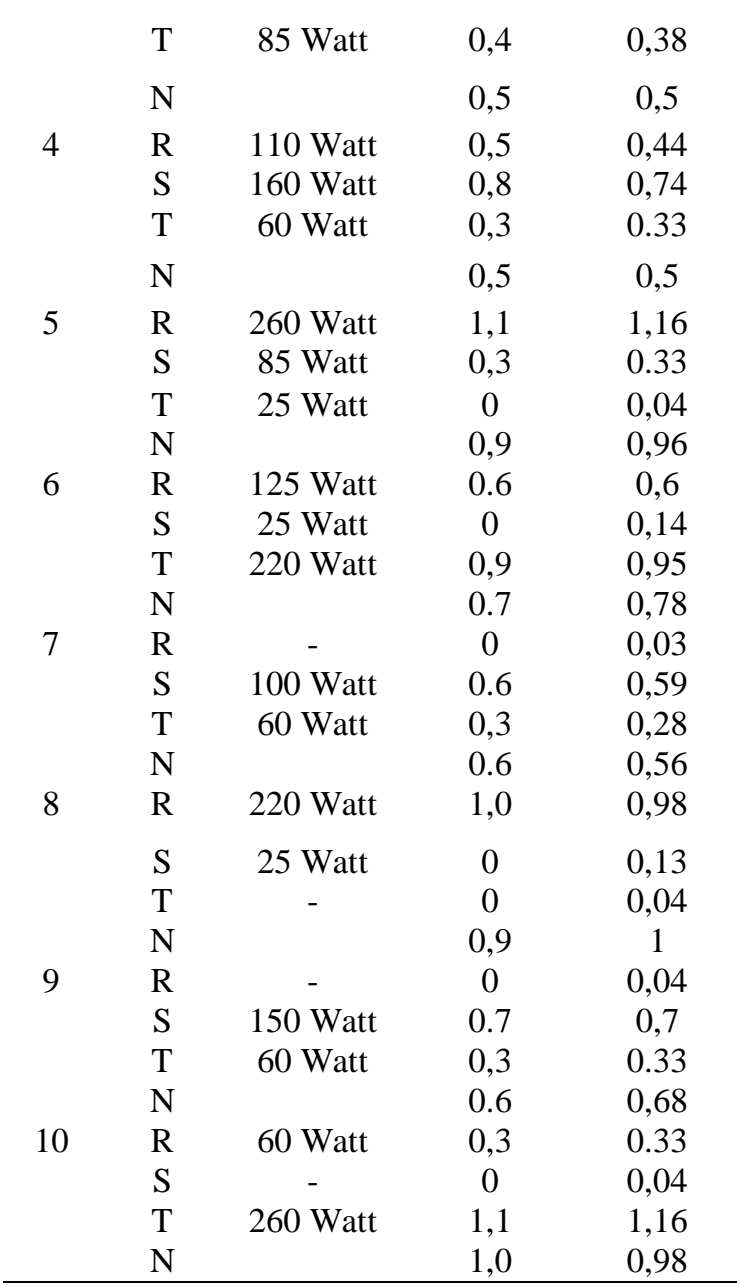

Tabel 2. Variasi beban seimbang

\begin{tabular}{|c|c|c|c|c|}
\hline No & Fasa & $\begin{array}{c}\text { Beban } \\
\text { Watt }\end{array}$ & $\begin{array}{c}\text { Arus } \\
\text { di } \\
\text { Tang } \\
\text { Ampe } \\
\text { re }\end{array}$ & $\begin{array}{c}\text { Arus } \\
\text { di } \\
\text { Scad } \\
\text { a }\end{array}$ \\
\hline \multirow[t]{4}{*}{1} & $\mathrm{R}$ & 125 Watt & 0.6 & 0,56 \\
\hline & S & 125 Watt & 0.6 & 0,56 \\
\hline & $\mathrm{T}$ & 120 Watt & 0,5 & 0,54 \\
\hline & $\mathrm{N}$ & - & 0 & 0,08 \\
\hline \multirow[t]{4}{*}{2} & $\mathrm{R}$ & 85 Watt & 0,4 & 0,39 \\
\hline & $S$ & 125 Watt & 0,5 & 0,54 \\
\hline & $\mathrm{T}$ & 160 Watt & 0.7 & 0,74 \\
\hline & $\mathrm{N}$ & & 0,3 & 0.33 \\
\hline \multirow[t]{4}{*}{3} & $\mathrm{R}$ & 150 Watt & 0.7 & 0,7 \\
\hline & S & 160 Watt & 0.7 & 0,74 \\
\hline & $\mathrm{T}$ & 60 Watt & 0,3 & 0.33 \\
\hline & $\mathrm{N}$ & & 0,4 & 0,44 \\
\hline \multirow[t]{4}{*}{4} & $\mathrm{R}$ & 160 Watt & 0.7 & 0,74 \\
\hline & $S$ & 150 Watt & 0.7 & 0,7 \\
\hline & $\mathrm{T}$ & 60 Watt & 0,3 & 0.33 \\
\hline & $\mathrm{N}$ & & 0,4 & 0,44 \\
\hline \multirow[t]{4}{*}{5} & $\mathrm{R}$ & 110 Watt & 0,5 & 0,54 \\
\hline & S & 160 Watt & 0.7 & 0,74 \\
\hline & $\mathrm{T}$ & 60 Watt & 0,3 & 0.33 \\
\hline & $\mathrm{N}$ & & 0,3 & 0,28 \\
\hline \multirow[t]{2}{*}{6} & $\mathrm{R}$ & 50 Watt & 0,3 & 0.25 \\
\hline & S & 100 Watt & 0.6 & 0,59 \\
\hline
\end{tabular}




\begin{tabular}{ccccc} 
& $\mathrm{T}$ & - & 0 & 0,04 \\
& $\mathrm{~N}$ & & 0,4 & 0,44 \\
7 & $\mathrm{R}$ & - & 0 & 0,04 \\
& $\mathrm{~S}$ & 85 Watt & 0,4 & 0,39 \\
& $\mathrm{~T}$ & 100 Watt & 0.6 & 0,59 \\
& $\mathrm{~N}$ & & 0,4 & 0,44 \\
\hline
\end{tabular}

Tabel 3. Percobaan Pengaman Beban Tidak Seimbang dengan melihat arus netral

\begin{tabular}{|c|c|c|c|c|c|}
\hline \multirow[t]{2}{*}{ No } & \multicolumn{3}{|c|}{$\begin{array}{c}\text { Beban Setiap Fasa } \\
\text { (Watt) }\end{array}$} & \multirow{2}{*}{$\begin{array}{c}\text { Arus } \\
\text { Netral } \\
\text { (A) }\end{array}$} & \multirow{2}{*}{$\begin{array}{c}\text { Kond } \\
\text { isi }\end{array}$} \\
\hline & $\mathrm{R}$ & $S$ & $\mathrm{~T}$ & & \\
\hline 1 & 50 & 160 & 160 & 0.44 & ON \\
\hline 2 & 200 & 120 & 50 & 0.6 & TRIP \\
\hline 3 & 85 & 200 & 85 & 0,5 & TRIP \\
\hline 4 & 110 & 160 & 60 & 0,5 & TRIP \\
\hline 5 & 260 & 85 & 25 & 0,96 & TRIP \\
\hline 6 & 125 & 25 & 220 & 0,78 & TRIP \\
\hline 7 & - & 100 & 60 & 0,56 & TRIP \\
\hline 8 & 220 & 25 & - & 1 & TRIP \\
\hline 9 & - & 150 & 60 & 0,68 & TRIP \\
\hline 10 & 60 & - & 260 & 0,98 & TRIP \\
\hline 11 & 125 & 125 & 120 & 0,08 & $\mathrm{ON}$ \\
\hline 12 & 85 & 125 & 160 & 0.33 & $\mathrm{ON}$ \\
\hline 13 & 150 & 160 & 60 & 0,44 & $\mathrm{ON}$ \\
\hline 14 & 160 & 150 & 60 & 0,44 & $\mathrm{ON}$ \\
\hline 15 & 110 & 160 & 60 & 0,28 & $\mathrm{ON}$ \\
\hline 16 & 50 & 100 & - & 0,44 & ON \\
\hline 17 & - & 85 & 100 & 0,44 & ON \\
\hline
\end{tabular}

\section{KESIMPULAN}

Berdasarkan perancangan, pengukuran dan percobaan yang telah dilakukan, dapat diambil kesimpulan sebagai berikut:

- Arus netral pada jaringan 3 fasa 4 kawat dapat muncul dari pemakian beban antar fasa yang tidak seimbang. Dalam ketidak seimbanganpun terdapat batas toleransi ketika muncul arus netral.

- Apabila arus netral yang muncul masih dalam batas toleransi, maka sistem akan bekerja secara normal, tetapi jika arus netral yang muncul sudah melebihi batas, maka Arduino akan memerintah kontaktor untuk trip.

- Sensor arus akan terus mendeteksi besaran beban yang terpasang pada setiap fasa dan pada penghantar netral, apabila sensor arus pada penghantar netral mendapat besaran sebesar nilai setting, maka Arduino akan memerintah kontaktor untuk trip.

- Untuk pemindahan taping fasa, dapat dilakukan melalui local maupun melalui layar HMI. Kedua cara ini sama-sama akan mengkontak relay yang terpasang pada sumber dan beban terlebih dahulu. Dan untuk mengkontaknya melalui perintah Arduino.
- Pemindahan taping fasa pada tiap beban harus bekerja dengan baik agar dapat menyeimbangkan beban dan diharapkan rugi-rugi daya yang diakibatkan arus netral yang muncul dapat di hindari seminimal mungkin.

\section{DAFTAR PUSTAKA}

1. Utami ,Purwanti Bekti. 2016. Studi Kasus Ketidakseimbangan Beban Dengan Perubahan Taping 1 Fasa Pada Penyulang Kalisari 05 Pt. Pln (Persero) Rayon Semarang Tengah. Tugas Akhir Tidak Terpublikasi. Semarang: Universitas Diponegoro.

2. Desiana, Catur. 2015. Perhitungan Susut Daya Listrik dan Simulasi Software ETAP 12.6.0 GunaMenjaga Mutu Tegangan di DaerahSawah Besar Raya Kaligawe Penyulang PDL.13 PT.PLN (Persero) Rayon Semarang Timur.Tugas Akhir Tidak Terpublikasi. Semarang: Universitas Diponegoro

3. Ghani, Reza Muhammad. 2016. Alat Pendeteksi Terputusnya Aliran Listrik Pada Jaringan Tegangan Menengah Satu Fasa Menggunakan Arduino Mega 2560 Dengan Memanfaatkan Aplikasi Web. Tugas Akhir Tidak Terpublikasi. Semarang: Universitas Diponegoro.

4. Arduino \& Genuino Products. Arduino MEGA 2560 \& Genuino MEGA2560. https://www.arduino.cc/en/Main/arduinoBoard Mega2560. Diakses tanggal 26 Juni 2017. 